\title{
Investigation of Natural Convection Heat Transfer Coefficient on Extended Vertical Base Plates
}

\author{
Mahdi Fahiminia ${ }^{1}$, Mohammad Mahdi Naserian ${ }^{2}$, Hamid Reza Goshayeshi ${ }^{1}$, Davood Majidian ${ }^{3}$ \\ ${ }^{1}$ Department of Mechanical Engineering, Mashhad Branch, Islamic Azad University, Mashhad, Iran \\ ${ }^{2}$ Young Researchers Club, Mashhad Branch, Islamic Azad University, Mashhad, Iran \\ ${ }^{3}$ Department of Systems Engineering, Virginia Polytechnic Institute and State University, USA \\ E-mail:MFahiminia@Gmx.com,Mmahnas@yahoo.com,Goshayshi@yahoo.com,DMajidian@yahoo.com \\ Received December 21, 2010; revised April 8, 2011; accepted April 15, 2011
}

\begin{abstract}
In this research, computational analysis of the laminar natural convection on vertical surfaces has been investigated. Natural convection is observed when density gradients are present in a fluid acted upon by a gravitational field. Our example of this phenomenon is the heated vertical plate exposed to air, which, far from the plate, is motionless. The CFD simulations are carried out using fluent software. Governing equations are solved using a finite volume approach. Coupling between the velocity and pressure is made with SIMPLE algorithm. The resultant system of discretized linear algebraic equations is solved with an alternating direction implicit scheme. Then a configuration of rectangular fins is put in different ways on the surface and natural convection heat transfer coefficient on these no slope surfaces is studied and finally optimization is done.
\end{abstract}

Keywords: Natural Convection, Vertical Surfaces, Simple Algorithm, Rectangular Fins

\section{Introduction}

In this document Natural convection is observed as a result of fluid movement which is caused by density gradient. A radiator which is used for warming the house is an example of practical equipment for natural convection. The movement of fluid, whether gas or liquid, in natural convection is caused by buoyancy force due to density reduction beside to surfaces in heating process. When an external force such as gravity, has no effect on the fluid there would be no buoyancy force, and mechanism would be conduction. But gravity is not the only force causing natural convection. When a fluid is confined in the rotating machine, centrifugal force is exerted on it and if one or more than one surfaces, with more or less temperature than that of the fluid are in touch with the fluid, natural convection flows will be experienced. The fluid which is adjacent to the vertical surface with constant temperature, the fluid temperature is less than the surface temperature, forms a velocity boundary layer. The velocity profile in this boundary layer is completely different with the velocity profile in forced convection. The velocity is zero on the wall due to lack of sliding. Then the velocity goes up and reaches its maximum and finally gets zero on the external border of velocity boundary layer. Since the factor that causes the natural convection, is temperature gradient, the heating boundary layer appears too. The temperature profile has also the same value as the temperature of wall due to the lack of particles sliding on the wall, and temperature of particles goes down as approaching to external border of temperature boundary layer and it would reach the temperature of far fluid. The initial enlargement of boundary layer is laminar, but in the distance from the uplifting edge, depending on fluid properties and the temperature difference of the wall and the environment, eddies will be formed and movement to turbulent zone will be started.

However, relatively little information is available on the effect of complex geometries on natural convection. Numerous experimental [1-4] and numerical [5] studies of rectangular fin heat sinks have been carried out [1]. Since the pioneering experimental work of Ray in 1920, natural or free convection has developed into one of the most studied topics in heat transfer. Jofre and Barron obtained data for heat transfer to air from vertical extended surface [2]. At $R a_{L}=10^{9}$ they quoted an improvement in the average Nusselt number of about $200 \%$ 
than to the turbulent predictions of Eckert and Jackson [3].

Bhavnani and Burgles [4] after several experiments proved that making special changes on vertical surfaces (horizontal little fins) reduces heat transfer in the natural convection heat transfer process. This conclusion can cause changes in the ways of insulating heat repelling surfaces and in this respect is of great importance. Numerical solution of the governing equations of boundary zones for vertical surfaces has been done by Helus and Churchill and step changes of surface temperature has been achieved $[8,9]$.

\section{Numerical Modeling}

The geometry of coordinate system which is used in this study and velocity boundary layer is shown in Figure 1. The governing equations in this study are as follows.

Continuity Equation:

$$
\frac{\partial(\rho u)}{\partial x}+\frac{\partial(\rho v)}{\partial y}+\frac{\partial(\rho w)}{\partial z}=0
$$

$\mathrm{X}$-Momentum Equation:

$$
\begin{aligned}
& \frac{\partial\left(\rho u^{2}\right)}{\partial x}+\frac{\partial(\rho u v)}{\partial y}+\frac{\partial(\rho u w)}{\partial z} \\
& =-\frac{\partial p}{\partial x}+\mu\left(\frac{\partial^{2} u}{\partial x^{2}}+\frac{\partial^{2} u}{\partial y^{2}}+\frac{\partial^{2} u}{\partial z^{2}}\right)+\frac{\partial}{\partial y}\left(\mu \frac{\partial u}{\partial y}\right)
\end{aligned}
$$

Y-Momentum Equation:

$$
\begin{aligned}
& \frac{\partial(\rho v u)}{\partial x}+\frac{\partial\left(\rho v^{2}\right)}{\partial y}+\frac{\partial(\rho v w)}{\partial z} \\
& =-\frac{\partial p}{\partial y}+\mu\left(\frac{\partial^{2} v}{\partial x^{2}}+\frac{\partial^{2} v}{\partial y^{2}}+\frac{\partial^{2} v}{\partial z^{2}}\right)+g\left(\rho-\rho_{\infty}\right)
\end{aligned}
$$

Z-Momentum Equation:

$$
\begin{aligned}
\frac{\partial(\rho w u)}{\partial x} & +\frac{\partial(\rho w v)}{\partial y}+\frac{\partial\left(\rho w^{2}\right)}{\partial z} \\
= & -\frac{\partial p}{\partial z}+\mu\left(\frac{\partial^{2} w}{\partial x^{2}}+\frac{\partial^{2} w}{\partial y^{2}}+\frac{\partial^{2} w}{\partial z^{2}}\right)
\end{aligned}
$$

Energy Equation:

$$
\begin{aligned}
\left(\frac{\partial(\rho u T)}{\partial x}\right. & \left.+\frac{\partial(\rho v T)}{\partial y}+\frac{\partial(\rho w T)}{\partial y}\right) \\
& =\frac{K}{C_{p}}\left(\frac{\partial^{2} T}{\partial x^{2}}+\frac{\partial^{2} T}{\partial y^{2}}+\frac{\partial^{2} T}{\partial z^{2}}\right)
\end{aligned}
$$

The density of air was calculated from the ideal gas law,

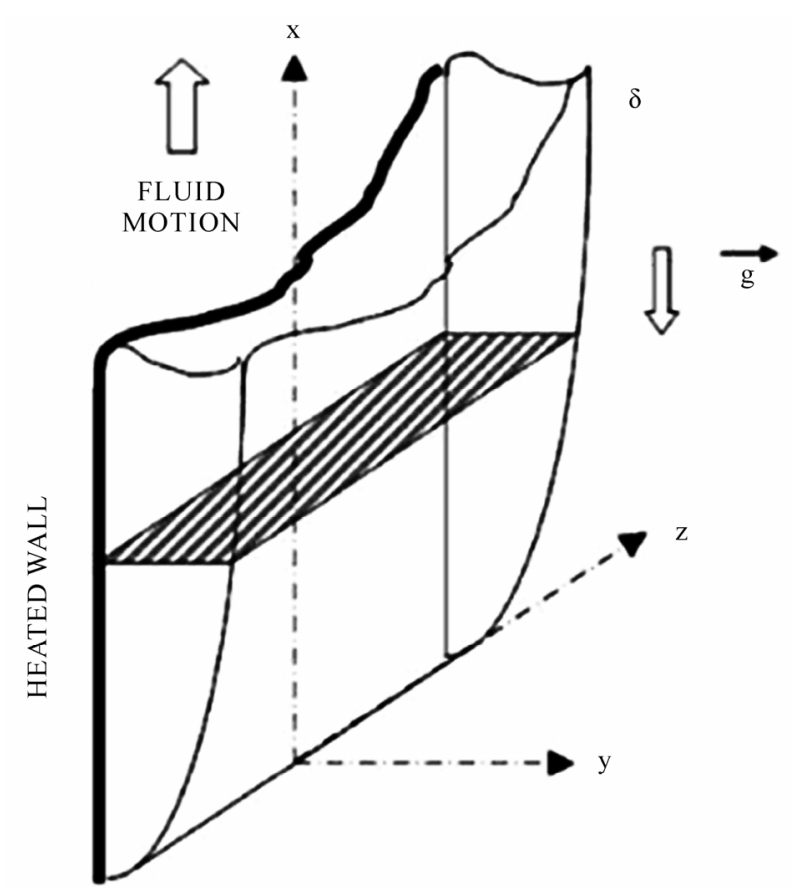

Figure 1. Geometry of coordinate system and velocity boundary layer.

$$
\rho=\frac{P_{a t m}}{\left(R_{c} / M_{w}\right) T}
$$

where Molecular weight of air is $28.966 \mathrm{~kg} / \mathrm{kmol}$.

Governing equations are solved using a finite volume approach. The convective terms are discretized using the power-law scheme, whereas for diffusive terms the central difference is employed. Coupling between the velocity and pressure is made with SIMPLE algorithm. The resultant system of discretized linear algebraic equations is solved with an alternating direction implicit scheme.

Figure 2 shows a heat sink with rectangular fins. The fins were arranged at regular intervals. The heat sink was made of aluminum. The dimensions of aluminum heat sink are listed in Table 1.

The properties of aluminum are listed in Table 2.

For the numerical analysis, the following assumptions were imposed.

1) The flow was steady, laminar, and three-dimensional.

2) Aside from density, the properties of the fluid were independent of temperature.

3) Air density was calculated by treating air as an ideal gas.

4) Radiation heat transfer was negligible.

\section{Results and Discussions}

The numerical simulation was conducted using Fluent 


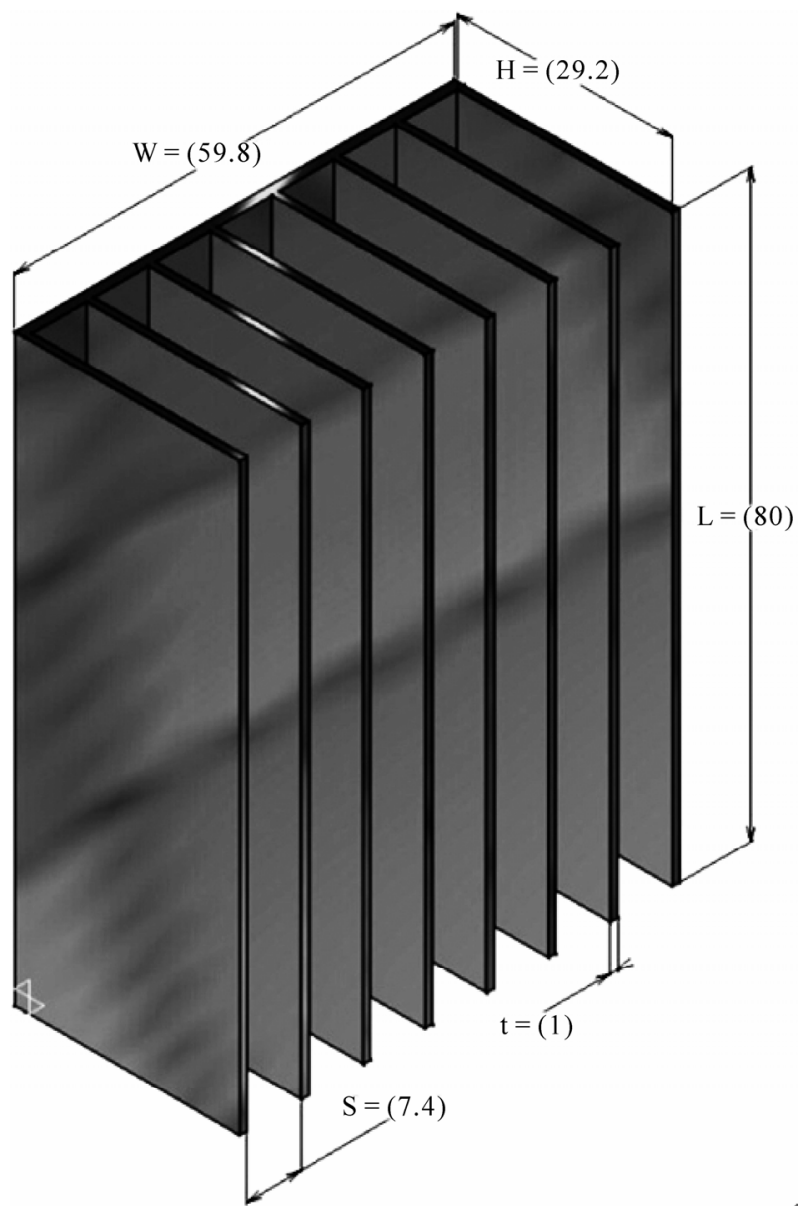

Figure 2. Fin configuration geometry.

Table 1. Dimensions of the fin configurations.

\begin{tabular}{cccc}
\hline $\begin{array}{c}\text { Fin length } \\
\mathrm{L}(\mathrm{mm})\end{array}$ & $\begin{array}{c}\text { Fin width } \\
\mathrm{W}(\mathrm{mm})\end{array}$ & $\begin{array}{c}\text { Fin thickness } \\
\mathrm{t}(\mathrm{mm})\end{array}$ & $\begin{array}{c}\text { Base thickness } \\
\mathrm{d}(\mathrm{mm})\end{array}$ \\
\hline 80 & 59.8 & 1 & 1.4 \\
\hline $\begin{array}{c}\text { Fin height } \\
\mathrm{h}(\mathrm{mm})\end{array}$ & $\begin{array}{c}\text { Fin spacing } \\
\mathrm{s}(\mathrm{mm})\end{array}$ & $\begin{array}{c}\text { Number of fin } \\
\mathrm{n}\end{array}$ & \\
\cline { 1 - 3 } 29.2 & 2.1 & 20 & \\
29.2 & 3.9 & 13 \\
29.2 & 7.4 & 8 \\
29.2 & 8.8 & 7 \\
29.2 & 13.7 & 5 \\
29.2 & 18.6 & 4 \\
\hline
\end{tabular}

Table 2. Air and heat sink properties.

\begin{tabular}{ccccc}
\hline Material & $C_{p}(\mathrm{~J} / \mathrm{kgK})$ & $\mu\left(\mathrm{N} / \mathrm{m}^{2} \mathrm{~s}\right)$ & $K(\mathrm{w} / \mathrm{mK})$ & $\rho\left(\mathrm{kg} / \mathrm{m}^{3}\right)$ \\
Air & 1006.3 & $1.853 \times 10^{-5}$ & $2.61 \times 10^{-5}$ & Equation (6) \\
Heat sink & 2800 & --- & 193 & 880 \\
\hline
\end{tabular}

V6.3, a commercially available CFD code based on the finite volume method. The grid dependence was investigated by varying the number of grid points from 22680 to 285714 . We selected 65016 grid points, additional grid points just vary the average heat sink temperature for the reference model, $n=20$, less than $0.5 \%$. The numerical results were validated with experimental data by comparing the differences between the ambient and heat sink temperatures. The geometric parameters of the experimental model were $n=20, L=59.8 \mathrm{~mm}, H=80 \mathrm{~mm}$, and $t=1 \mathrm{~mm}$ [10]. Figure 3 compares the temperature differences between the experimental and numerical results in terms of the heat flux applied to the heat sink base. This implies that the present numerical model can correctly predict the natural convection flow around a rectangular heat sink.

Variation of convective rate with base-to-ambient temperature difference at $H=29.2 \mathrm{~mm}$ and $L=80 \mathrm{~mm}$ is studied in Figure 4, the convective heat transfer rate first increases with increasing of fin spacing, reaches a maximum, and with further increases of fin spacing starts to decrease. The value of the fin spacing at which the convective rate is maximized, is called optimum fin spacing, Inspection of Figure 4 reveals that the optimum fin spacing varies between 5.84 and $6.42 \mathrm{~mm}$ at different base-to-ambient temperature difference. The dependence of optimum fin spacing on base-to-ambient temperature difference is not very strong. For a given fin height and fin length, the values for optimum fin spacing do not vary more than $0.4 \mathrm{~mm}$.

The values of natural convection heat transfer coefficient obtained for different base-to-ambient temperature difference is shown in Figure 5, as is seen, the natural convection coefficient increases substantially as the gap between fins increases from 2.1 to $18.6 \mathrm{~mm}$, and then flattens out with further increases in gap.

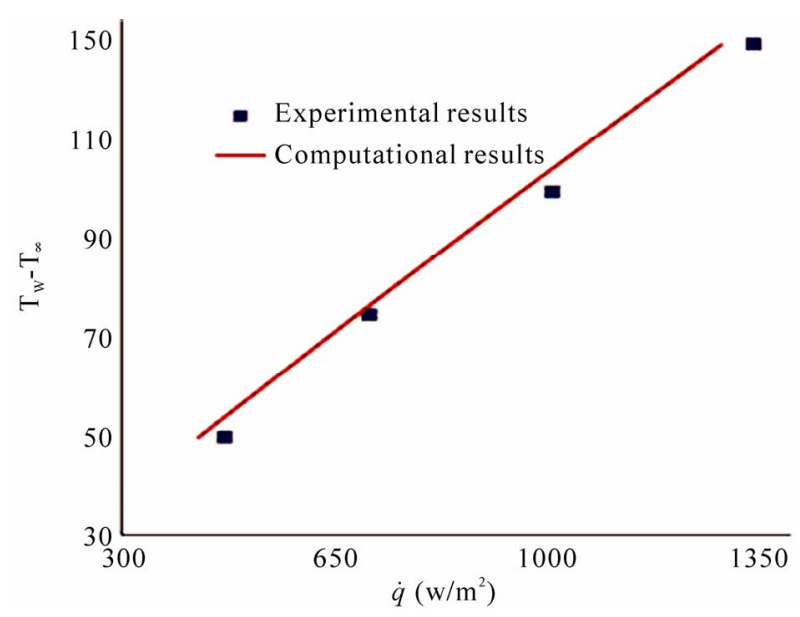

Figure 3. Comparison between experimental [10] and computational results. 


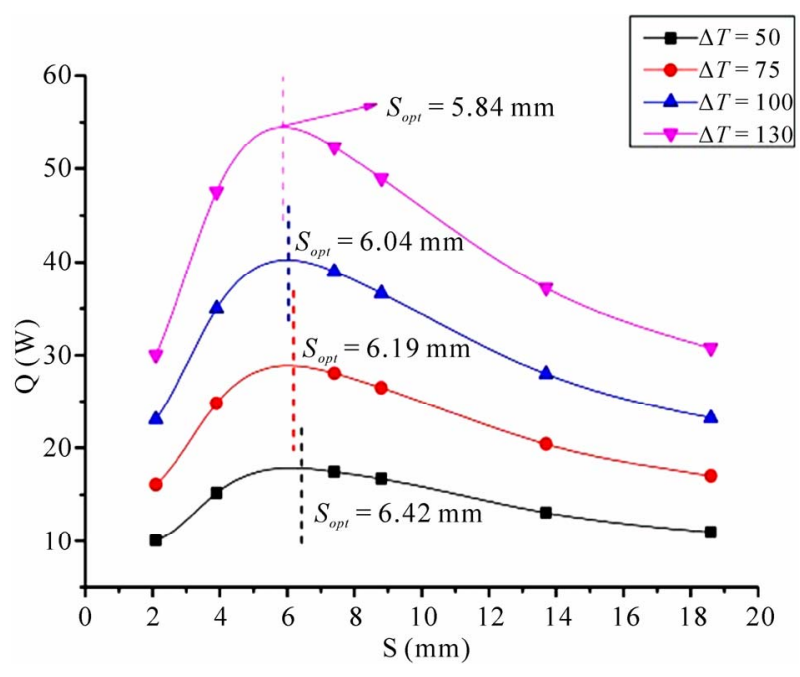

Figure 4. Variation of convective rate with base-to-ambient temperature difference at $H=29.2 \mathrm{~mm}$ and $L=80 \mathrm{~mm}$.

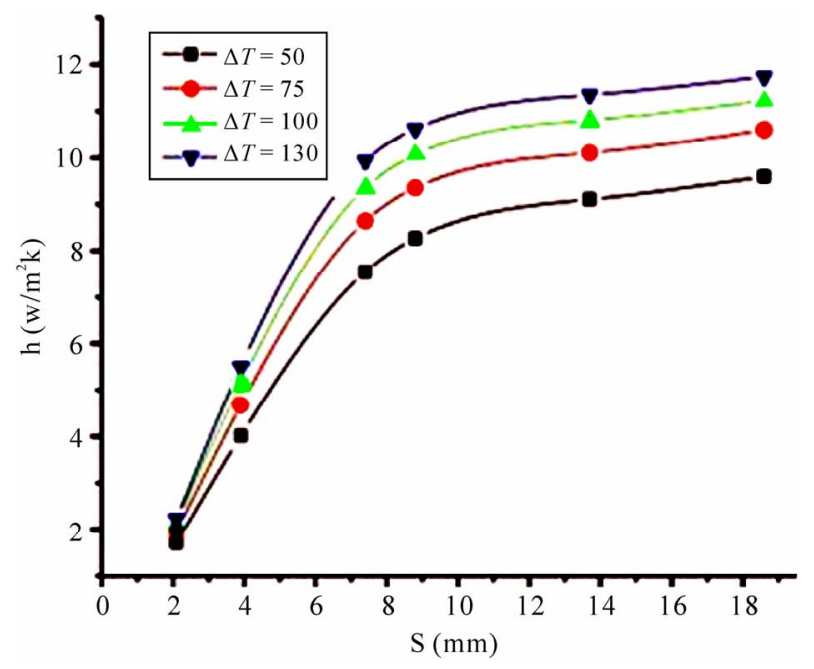

Figure 5. Natural convection heat transfer coefficients for different heat sinks.

If the fins are closely spaced, the heat transfer coefficient (h) is lower because mixing of the boundary layer occurs (the fills up with warm air). The graph if Figure 5 clearly shows that the heat transfer coefficient decreases as the gap between fins decreases. However, if the fins are closely spaced, there is also more dissipating surface area (more fins for a given volume). The additional surface area can counteract the reduced heat transfer coefficient. This can be seen by examining the graph of total wattage dissipated in Figure 4. For the $80 \mathrm{~mm}$ X 59.8 $\mathrm{mm}$ vertical-heat sink shown in the graph, the spacing of $7.4 \mathrm{~mm}$ provided the optimal combination of heat transfer coefficient and dissipating surface area. For studying the growth of boundary layer between two adjacent fins, the temperature contour of heat sinks is investigated. The results can be seen in Figures 6 and 7.
According to Figure 6, it is gotten out that the boundary layer interferences occur immediately after air enters to the channels of the fin array and the flow through each channel of the array is fully developed.

To determine the order of magnitude of fin spacing for the maximum convection heat transfer rate from the fins, the following two extreme conditions are considered:

1) Limiting cases of very small value of s (small-s limit).

2) Opposing limiting cases in which the fin spacing $s$, is large (large-s limit).

In the small-s limit, it is assumed that the boundary layer interferences occur immediately after air enters to the channels of the fin array and the flow through each channel of the array is fully developed channel flow. The total heat transfer rate from a single channel is calculated from

$$
\dot{Q}_{\text {c single channel }}^{1}=\dot{m} C_{P} \Delta T
$$

From the scale analysis of continuity and momentum equations a balance between mass flow rate and other parameters can be written as [10]

$$
\dot{m} \approx \frac{\rho g \beta s^{3} \Delta T}{v} H
$$

If the number of channels (or the fins) is defined as $n=$ $\mathrm{W} / \mathrm{s}$, then the total heat transfer rate from the fins may be expressed as

$$
\begin{gathered}
\dot{Q}_{c}^{1} \approx \frac{\rho g \beta s^{3} \Delta T}{v} H C_{p} \Delta T \frac{W}{S} \\
\dot{Q}_{c}^{1}=\dot{Q}_{c}-\left(\dot{Q}_{0}\right)_{c}
\end{gathered}
$$

In Equation (10), both $\dot{Q}_{c}$ and $\left(\dot{Q}_{0}\right)$ are evaluated at the same base-to-ambient temperature difference. Introducing the thermal diffusivity, $\alpha$ into Equation (9), the following equation is obtained as

$$
\dot{Q}_{c}^{1} \approx \frac{g \beta s^{3} \Delta T}{v \alpha} H k \Delta T \frac{W}{S}
$$

As seen from Equation (11), in the small-s limit, the total heat convection heat transfer rate is directly proportional with $s^{2}$. In opposing for large gap, as is shown in Figure 6, the boundary layer thickness is much smaller than the fin spacing. Each channel looks like the entrance region to parallel-plate duct in which the boundary layers develop without any interference. The total convection heat transfer rate from two sides of a single fin can be expressed as

$$
\dot{Q}_{c \text { Fin }}^{1} \approx h A \Delta T
$$

where $h$ is the heat transfer coefficient over single fin, $A$ is the area of single fin. 

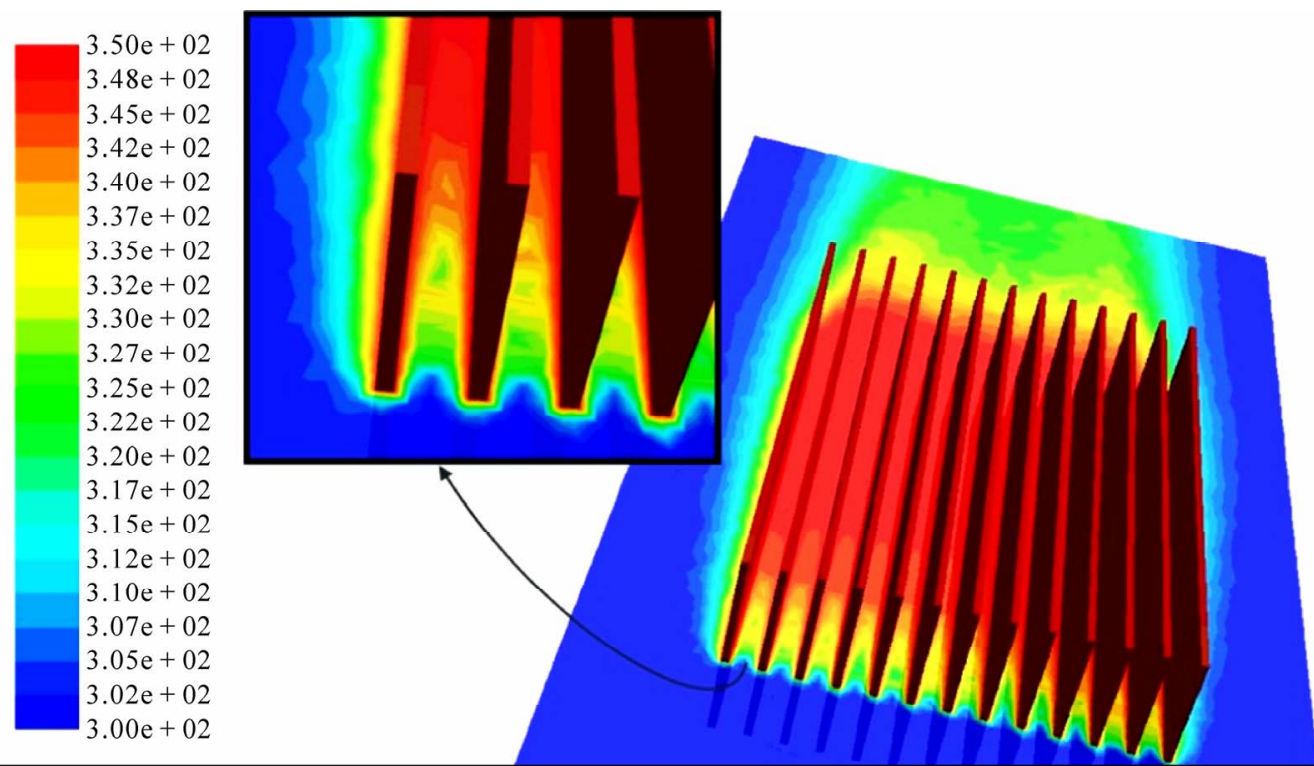

Contours of Static Temperature (k)

Figure 6. Variation of temperature contour of the heat $\operatorname{sink}(s=3.9 \mathrm{~mm})$.
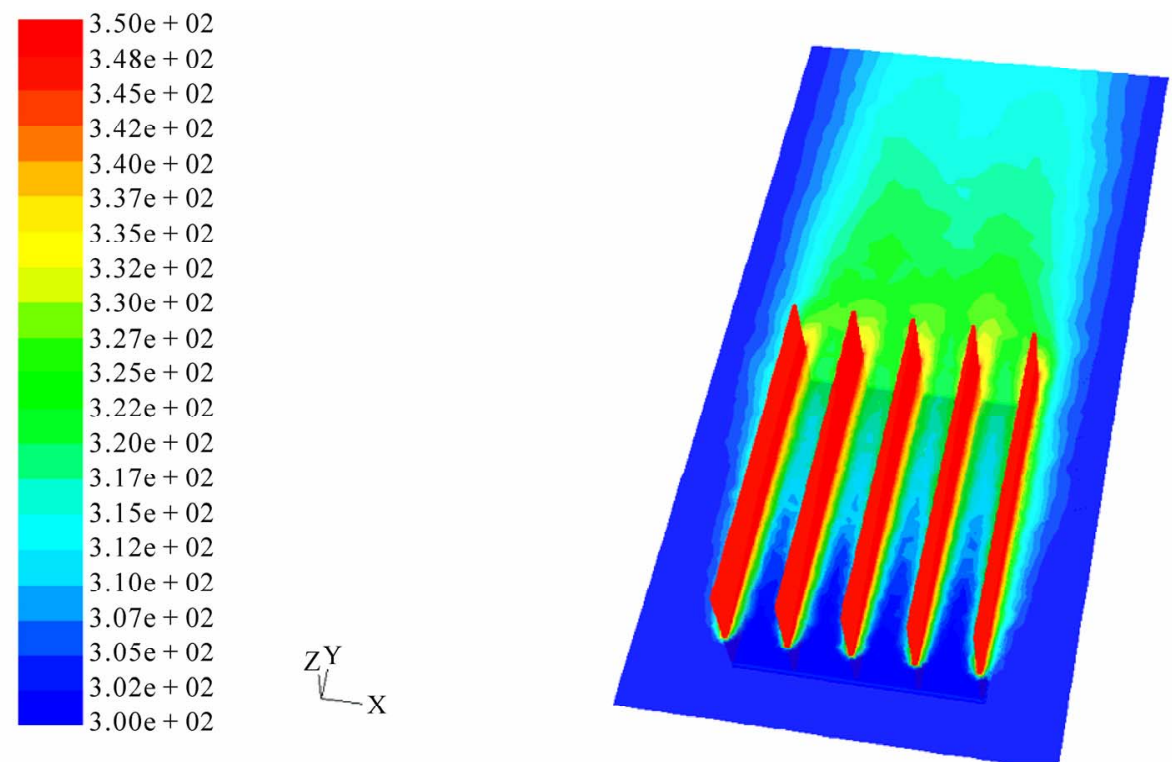

Figure 7. Variation of temperature contour of the heat $\operatorname{sink}(s=13.7 \mathrm{~mm})$.

Using momentum and energy equations, heat transfer coefficient can be written as

$$
h \approx\left(\frac{\rho g \beta L^{3} \Delta T}{v \alpha}\right)^{\frac{1}{4}} \frac{k}{L}
$$

If the area of the single fin is scaled as $\mathrm{A}=\mathrm{H} \mathrm{X} \mathrm{L}$ and the number of fins is expressed as $n=\mathrm{W} / \mathrm{s}$, then the total convective heat transfer rate from the fins can be expressed as

$$
\dot{Q}_{c}^{2} \approx\left(\frac{\rho g \beta L^{3} \Delta T}{v \alpha}\right)^{\frac{1}{4}} k H \Delta T \frac{W}{s}
$$

Equation (14) indicates that, in the large-s limit, the 
convective heat transfer rate from the fins is inversely proportional with $s$. In Figure 7, this trend is indicated by large-s asymptote. The relations obtained for two extreme conditions are two asymptotes of convective heat transfer, $\dot{Q}_{c}^{1}$ or $\dot{Q}_{c}^{2}$ versus fin spacing. As a result of the analysis made for the case of small-s limit, it is estimated that the total convective heat transfer rate is proportional with $s^{2}$. On the other hand, in the case of large-s limit, the total heat transfer rate is inversely proportional with fin spacing.

$$
\dot{Q}_{c}^{2}=\dot{Q}_{c}-\left(\dot{Q}_{0}\right)_{c}
$$

Solving Equation (12) for fin spacing, the order of magnitude of optimum fin spacing, $s_{\text {opt }}$ for maximum heat transfer rate can be obtained as,

$$
\dot{Q}_{c}^{1}=\dot{Q}_{c}^{2}
$$

For dimensionless presentation of the order of magnitude of optimum fin spacing, the Rayleigh number is employed according to its definition.

$$
\frac{S_{o p t}}{L} \approx R a_{L}^{-\frac{1}{4}}
$$

As in Figure 4, the investigations show that in the same fin length and height and constant base-to-ambient temperature difference, the optimum fin spacing is the space which is not too large, like Figure 6, nor too small, like Figure 7, and the value of it, is between these two values. Figure 8 show the temperature contour of heat sink with optimum fin spacing.

$$
R a_{L}=\left(\frac{\rho g \beta L^{3} \Delta T}{v \alpha}\right)
$$

\section{Conclusions}

From these figures it can also be seen that, at a given fin height and temperature difference, the convection rates increases with increasing fin spacing and reaches a maximum. With further increases of fin spacing, rate starts to decrease. The occurrence of this maximum has significant practical applications for optimum performance of fin-arrays. It would be appropriate to manufacture the fin array with aforementioned fin height and spacing. The values of coefficient obtained for an ambient air temperature of $27^{\circ} \mathrm{C}$ and plate surface temperatures of $77,102,127$ and $157^{\circ} \mathrm{C}$ appear in Figure 5. As may be seen, the natural convection coefficient increases substantially as the gap between fins increases from 2.1 to $18.6 \mathrm{~mm}$, and then flattens out with further increases in gap. It may be noted that the values shown for a gap of $18.6 \mathrm{~mm}$ are within a few per cent of those obtained using a correlation for an individual vertical plate.

These figures show that, the convective heat transfer rate from fin arrays depends on fin height, fin length, fin spacing and base-to-ambient temperature difference. The convective heat transfer rates from the fin arrays increases with fin height, fin length and base-to-ambient temperature difference. The heat transfer rate increases monotonously with temperature difference between fin
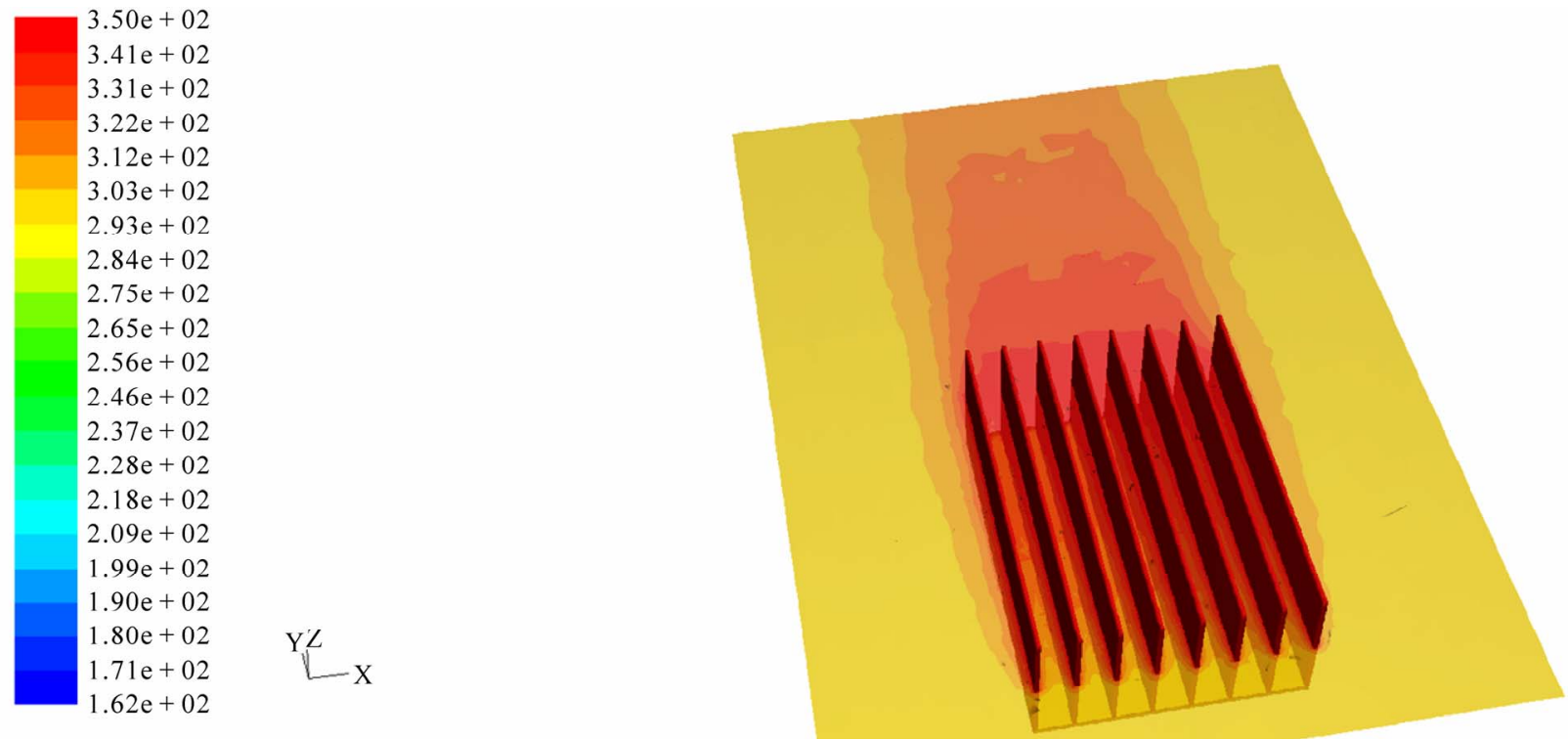

Figure 8. Variation of temperature contour of the heat sink. 
base and surroundings, Tw-Ta. If the distance between the fins is selected properly, there will be no interference between boundary layers of two adjacent fins and the surfaces. For stating the magnitude of fin spacing for having the best convection rates of fins, we choose thedistance between the fins big enough so that the thickness of boundary layer is smaller than the distance between the fins and increases without any interfering.

\section{References}

[1] O. G. Martynenko and P. Khramtsov, "Free-Convection Heat Transfer," Springer, New York, 2005.

[2] R. J. Jofre and R. F. Baron, "Free Convection to a Roughplate," American Society of Mechanical Engineers Paper, Vol. 33, No. 67, 1986, pp. 965-981.

[3] E. R. G. Eckert and T. W. Jackson, "Analysis of Turbulent Free Convection Boundary Layer on Flat Plate," NCA Report 1015, Vol. 1, No. 2, 1951, pp. 257-261.

[4] A. E. Bergles and G. H. Junkhan, "Energy Conservation via Management Quarterly," Progress Report, No. COO4649-59, 31 March 1979, pp. 346-348.

[5] S. H. Bhavnani and A. E. Bergles, "Effect of Surface Geometry and Orientation on Laminar Natural Convection from a Vertical Flat Plate with Transverse Rough- ness Elements," International Journal of Heat Mass Transfer, Vol. 33, No. 5, 1990, pp. 965-981.

doi:10.1016/0017-9310(90)90078-9

[6] P. E. Rubbert, "The Emergence of Advanced Computational Methods in the Aerodynamic Design of Commercial Transport Aircraft," Proceedings of International Symposium on Computational Fluid Dynamics, Vol. 1, No. 4, 1984, pp. 42-48.

[7] S. W. Churchill and R. Usagi, "A General Expression for the Correlation of Rates of Transfer and other Phenomena," AIChe Journal, Vol. 18, No. 6, 1972, pp. 11211128. doi:10.1002/aic.690180606

[8] H. P. Kavehpour, M. Faghri and Y. Asako, "Effects of Compressibility and Rarefaction on Gaseous Flows in Microchannels," An International Journal of Computation and Methodology, Vol. 32, No. 7, 1997, pp. 41-47. doi: 10.1080/10407789708913912

[9] D. D. Gray and A. Giorgini, "The Validity of the Boussinesq Approximation for Liquids and Gases," International Journal of Heat and Mass Transfer, Vol. 19, No. 5, pp. 545-551, 1976. doi:10.1016/0017-9310(76)90168-X

[10] B. Yazicioğlu and H. Yüncü, "Optimum Fin Spacing of Rectangular Fins on a Vertical Base in Free Convection Heat Transfer," Journal of Heat Mass Transfer, Vol. 44, No. 1, pp. 11-21. doi: 10.1007/s00231-006-0207-6

\section{Nomenclature (List of Symbols)}

\begin{tabular}{llc}
\hline Symbol & \multicolumn{1}{c}{ Quantity } & Unit \\
\hline$A$ & area & $\mathrm{m}^{2}$ \\
$h$ & convection heat transfer coefficient & $\mathrm{w} / \mathrm{m}^{2} \mathrm{k}$ \\
$T$ & temperature & $\mathrm{k}$ \\
$C p$ & specific heat at constant pressure & $\mathrm{kJ} / \mathrm{kgk}$ \\
$g$ & gravitational acceleration & $\mathrm{m} / \mathrm{s}^{2}$ \\
$H$ & fin height & $\mathrm{m}$ \\
$k$ & thermal conductivity & $\mathrm{w} / \mathrm{mk}$ \\
$L$ & fin length & $\mathrm{m}$ \\
$\dot{m}$ & mass flow rate & $\mathrm{kg} / \mathrm{s}$ \\
$\beta$ & volumetric thermal expansion coefficient & $1 / \mathrm{k}$ \\
\hline
\end{tabular}

\begin{tabular}{clc}
\hline$n$ & number of fins & - \\
$s$ & fin spacing & $\mathrm{m}$ \\
$t$ & fin thickness & $\mathrm{m}$ \\
$\mathrm{W}$ & base plate width & $\mathrm{m}$ \\
$\dot{Q}_{c}^{1}$ & convection rate from fins in small-s limit & $\mathrm{W}$ \\
$\dot{Q}_{c}^{2}$ & convection rate from fins in large-s limit & $\mathrm{w}$ \\
$\dot{Q}_{c}$ & convection rate & $\mathrm{w}$ \\
$R a$ & Rayleigh number & - \\
$T_{w}$ & base plate temperature & $\mathrm{k}$ \\
$T_{a}$ & ambient temperature & $\mathrm{k}$ \\
$v$ & kinematic viscosity & $\mathrm{m}^{2} / \mathrm{s}$ \\
$\alpha$ & thermal diffusivity & $\mathrm{m}^{2} / \mathrm{s}$ \\
\hline
\end{tabular}

